\title{
Validation of the content of the prevention protocol for early sepsis caused by Streptococcus agalactiae in newborns
}

\author{
Fabiana Alves da Silva ${ }^{1}$ \\ Cláudia Fernanda de Lacerda Vidal ${ }^{2}$ \\ Ednaldo Cavalcante de Araújo ${ }^{3}$
}

\begin{abstract}
Objective: to validate the content of the prevention protocol for early sepsis caused by Streptococcus agalactiae in newborns. Method: a transversal, descriptive and methodological study, with a quantitative approach. The sample was composed of 15 judges, 8 obstetricians and 7 pediatricians. The validation occurred through the assessment of the content of the protocol by the judges that received the instrument for data collection - checklist - which contained 7 items that represent the requisites to be met by the protocol. The validation of the content was achieved by applying the Content Validity Index. Result: in the judging process, all the items that represented requirements considered by the protocol obtained concordance within the established level (Content Validity Index $>0.75$ ). Of 7 items, 6 have obtained full concordance (Content Validity Index 1.0) and the feasibility item obtained a Content Validity Index of 0.93. The global assessment of the instruments obtained a Content Validity Index of 0.99 . Conclusion: the validation of content that was done was an efficient tool for the adjustment of the protocol, according to the judgment of experienced professionals, which demonstrates the importance of conducting a previous validation of the instruments. It is expected that this study will serve as an incentive for the adoption of universal tracking by other institutions through validated protocols.
\end{abstract}

Descriptors: Validation Studies; Streptococcus Agalactiae; Sepsis; Infant, Newborn.

\footnotetext{
${ }^{1}$ Specialist, RN Midwife, Hospital Universitário de Santa Maria, Santa Maria, RS, Brazil.

2 PhD, Physician, Hospital das Clínicas, Universidade Federal de Pernambuco, Recife, PE, Brazil.

3 PhD, Adjunct Professor, Departamento de Enfermagem, Universidade Federal de Pernambuco, Recife, PE, Brazil.
}

Corresponding Author: Fabiana Alves da Silva

Universidade Federal de Pernambuco. Hospital das Clínicas

Comissão de Controle de Infecção Hospitalar

Av. Prof. Moraes Rego, 1235

Cidade Universitária

CEP: 50670-901, Recife, PE, Brasil

E-mail: fabyanasylva_85@hotmail.com
Copyright (c) 2015 Revista Latino-Americana de Enfermagem This is an Open Access article distributed under the terms of the Creative Commons Attribution Non-Commercial License (CC BY-NC).

This license lets others distribute, remix, tweak, and build upon your work non-commercially, and although their new works must also acknowledge you and be non-commercial, they don't have to license their derivative works on the same terms. 


\section{Introduction}

The neonatal infection by the $B$ group $\beta$-hemolytic Streptococcus (EGB), or Streptococcus agalactiae, is considered an important problem of public health, being the main cause of early neonatal sepsis, the generalized infection that occurs on the first 48 hours of life, having a direct relationship with the gestational or intra-partum period, according to the definition by the Brazilian Ministry of Health. The sepsis represents one of the most important causes of neonatal morbidity and mortality, and its incidence varies from one to eight cases for every thousand born alive. In Brazil, the rate of mortality is around $25 \%$. International databases demonstrate that around 30 million of newborns are diagnosed with sepsis and from one to two million of them die.

Among other complications due to the infection by the Streptococcus agalactiae in newborns some of them need to be emphasized: meningitis, pneumonia, septic abortion, chorioamnionitis, endometritis, increase in mortality and morbidity, neurological deficit, long-term hospital confinement and neonatal decease. Vertical transmission is the most common and its determining factor is the exposure of the newborn to the EGB that are present in the vagina, which is colonized in the intra-partum period ${ }^{5}$. Among the newborns of mothers that possess the EGB, the colonization occurs in $50 \%$ of the cases. Considering the prevalence of the national maternal colonization in $20 \%$, there will be incidence of two cases for every thousand born, provided the absence of prophylactic interventions.

With the understanding of the relevance of this issue in the context of public health, in the late 1990's, a process of implementation of prophylactic interventions started, intending to control the EGB infection in newborns, which were improved through time. In 1996, the Center for Diseases Control and Prevention (CDC) published in the USA the first national consensus directives about perinatal prevention of infections caused by Streptococcus agalactiae. Two prophylactic strategies for the intra-partum period were established. The first was based on the risk factors and the second in the results of the tracking on the genitorectal secretion cultures, collected between the $35^{\text {th }}$ and the $37^{\text {th }}$ week of pregnancy, for the EGB research.

In August 2002, based on the new evidences of a retrospective study, these directives were updated, being now recommended the universal tracking through genitorectal culture between the $35^{\text {th }}$ and the $37^{\text {th }}$ week of gestation as the only strategy for the orientation of the intra-partum chemoprophylaxis of the early infection by the EGB. This approach consists in doing a microbiological examination, with the goal of limiting, in terms of candidacy to the intra-partum prophylaxis, just the patients colonized by the EGB, regardless of the risk factors. This study demonstrated that the effectiveness of the late antenatal tracking, through the EGB culture, was $50 \%$ superior to the alternate approach based on the risk factors.

In 2010, the $3^{\text {rd }}$ review of the directives based on the updated evidences of perinatal prevention for the EGB was published. The CDC 2010 version highlights the indications for universal "screening" on the $3^{\text {rd }}$ trimester of the gestation, standardizing the laboratory methods about the collection and transportation of samples for the detection of the GBS, taking into consideration the changes in the arrangement and of the indication of the antimicrobials recommended for the intrapartum prophylaxis and by supplying updates for the recommendations for newborns at risk to have an early infection.

The change of conduct in the USA, through the implementation of the orientations established by the CDC, suggests a decline in the incidence of the early disease caused by the EGB in the country, provided that, among newborns with up to 6 days of life, the incidence of the B group streptococcus disease was reduced from 0.47 of a thousand successful births, between 1999 and 2001 , to 0.34 of a thousand successful births, between 2003 and 2005, which corresponds to a reduction of $27 \%$ after the implementation of the CDC 2002 guide. Other data evinced that in the USA there was a reduction equivalent to $1.2 \%$ in the annual rate of hospitalization among the pre-term newborns, between 1988 and 2006, and that can be a consequence of the results of the implementation of the preventive measures.

The Hospital das Clínicas of the Federal University of Pernambuco (HC/UFPE) did not have the protocol for the prevention of the neonatal infection by the EGB. This way, the genitorectal culture is not done frequently, which makes it impossible to know the state of the maternal colonization. Given that, the prevention of the perinatal infection by $E G B$ is done through the administration of the intra-partum antibiotic in pregnant women that present risk factors on neonatal transmission, such as the long period necessary for the rupture of the amniotic membrane and the premature labor. However, this approach presents a limited efficiency and such indiscriminate use of antibiotics, in all pregnant women with risk factors, may contribute for the emergence of new and more resistant strains. 
Given the available evidences about the relevance of the infection within public health policies, the consequences for the concept and the precision of the intra-partum prophylaxis based on the universal tracking, it was developed a protocol for the prevention of the neonatal sepsis by the EGB, based on the recommendations of the CDC 2010 guide, to be implemented in the pre-natal, obstetrics and neonatal units of the HC/UFPE.

Taken into consideration the importance of the adequacy of the protocol regarding the semantic and content aspects, the validation of the content by judges emerge as a tool to meet this requirement, because it allows professionals that are experienced in this area to provide significant collaborations to the protocol.

Provided what was mentioned previously, this study had the goal of validating the content of the prevention protocol of the early sepsis caused by the Streptococcus agalactiae in newborns.

\section{Method}

This is a transversal, descriptive and methodological study with a quantitative approach, conducted at the $\mathrm{HC} / U F P E$, an institution specialized in the care of highrisk pregnancies, between May and August 2013.

The population was made of obstetricians and pediatricians from the Obstetrics Center at the HC/UFPE, with a minimum experience of four years in pediatrics or obstetrics. The sample, by willfulness, included 10 obstetricians and 10 pediatricians. These were included due to a 4 year minimum experience in neonatology at the $\mathrm{HC} /$ UFPE. The adopted criteria for exclusion were the following: failure to deliver the questionnaire within the established deadline or the inadequate filling of the questionnaires.

The validation by the judges occurred through the evaluation of the content of the protocol for the prevention of neonatal sepsis caused by EGB, based on the CDC 2010 guide. Through this, the contact was established in order to invite pediatricians and obstetricians to participate in the research. For all those that accepted participating, the protocol that was made to meet the requirements of the study was delivered, as well as a letter containing the objectives of the study, the justification of the process of the assessment protocol and the instrument for the data collection, a checklist containing seven items that represent the requisites to be met by the protocol.

The evaluation of the instrument occurred from the classification of every item in terms of being adequate, partially adequate or inadequate. The ones considered adequate were those that completely met the established requirement; partially adequate were those that required some changes; and inadequate were those that expressed a complete non-compliance in relation to the established criteria.

The judges were instructed to give the material back after the analysis and to give their final opinion personally to the researchers, within the 30 day deadline. For the cases in which were considered to have inadequacies, the reasons were explained, the suggestions described and the contents rewritten, improved and submitted to a new assessment. To the judges were also granted explanations, when they were requested, related to the practices established in the protocol.

The variables that were analyzed were: vocabulary, relevance, clinical-scientific aspects, clarity, feasibility, organization and scope. After the assessment of the protocol, the validation of the content was done, with the application of the Content Validity Index (CVI) that measures the proportion or percentage of the judges that express agreement in relation to the instrument's items.

The specialized literature presents different possibilities for the calculation of the CVI, as well as for the establishment of its minimum level of concordance. It is possible to calculate the score of this Index by adding up the items that were deemed relevant. In the case of this study, it was considered an adequate judgment by all judges. The CVI calculation for the instrument, as a whole, was done through the addition of all the CVIs, calculated separately, divided by the number of items of the instruments. It was considered the minimum concordance index for the CVI the number 0.75 , by consensus, both for the assessment of every item and the instrument general assessment.

The data collected were electronically processed, with the aid of the Excel 20 program. For the analysis the manual calculation of the CVI was applied, as it was previously described and percentages for the characterization of the sample were utilized.

All the judges were informed about the goals of the research, being included only the participants that signed the Informed Consent Form. The ethical aspects were observed, with respect to the Resolution 466/2012 of the Brazilian National Health Council (CNS). The data collection started after the approval of the project by the Research Ethics Committee of the Center of Health Sciences at the Federal University of Pernambuco (ruling 487.861). 


\section{Results}

Initially, the sample included 20 judges. However, there were 5 exclusions: 2 for refusal in participating in all phases, 1 for inadequate filling of the form, 1 for not returning the material and 1 that abandoned. This way, the sample was made up by 15 judges, 8 obstetricians and 7 pediatricians. Table 1 shows the characterization of the judges.

Table 1 - Data related to the identification of the judges, according to gender, experience and titration. Recife, PE, Brazil, 2013.

\begin{tabular}{lll}
\hline Variables & $\mathbf{n}$ & $\%$ \\
\hline Gender & 9 & 60.0 \\
Feminine & 6 & 40.0 \\
$\quad$ Masculine & & \\
Titration & 8 & 53.3 \\
$\quad$ Specialization & 5 & 33.3 \\
Master's Degree & 2 & 13.3 \\
PhD & & \\
Experience & 1 & 6.5 \\
6 to 10 years & 14 & 93.5 \\
$>10$ years & 15 & 100.0 \\
Total & & \\
\hline
\end{tabular}

It can be observed in Table 1 that among the participants there was the prevalence of the feminine gender $(9=60 \%)$. The experience years varied from 10 to 38 years, and 14 (93.5\%) of the judges had an experience time greater than 10 years. Regarding the titration, 5 (33.3\%) had a Master's degree and 2 (13.3\%) had a PhD.

As it was demonstrated in Table 2, in the process of judging the requisites related to the protocol of prevention of the neonatal sepsis caused by EGB, after the first assessment which was done by the judges no item was deemed as inadequate. However, only the item relevance had total approval (CVI 1.0) and the others required changes. It was observed that the items vocabulary, clarity and feasibility had a CVI below the established level (CVI < 0.75).

When the protocol was submitted for a new analysis after its correction, considering the suggestions of the judges, all the items obtained concordance within the established level (CVI > 0.75). Of the 7 items, 6 obtained full concordance (CVI = 1.0) and the item Feasibility obtained a CVI of 0.93. The global assessment of the instruments had a CVI of 0.99 , demonstrating concordance within the established level (Table 3).

Table 2 - First step of judgment made by the judges about the items of the protocol of prevention of the early infection by the Streptococcus agalactiae in a newborn. Recife, PE, Brazil, 2013.

\begin{tabular}{|c|c|c|c|c|c|}
\hline \multirow{3}{*}{ Items } & \multicolumn{4}{|c|}{ Judgment } & \multirow{3}{*}{$\mathrm{CVI}^{*}$} \\
\hline & \multicolumn{2}{|c|}{ Adequate with alterations } & \multicolumn{2}{|c|}{ Adequate } & \\
\hline & $\mathbf{N}$ & $\%$ & $\mathbf{N}$ & $\%$ & \\
\hline Vocabulary & 4 & 26.5 & 11 & 73.5 & 0.73 \\
\hline Relevance & - & - & 15 & 100 & 1.0 \\
\hline Clínical-Scientific Aspects & 2 & 13.5 & 13 & 86.5 & 0.86 \\
\hline Clarity & 5 & 33.5 & 10 & 66.5 & 0.66 \\
\hline Feasibility & 5 & 33.5 & 10 & 66.5 & 0.66 \\
\hline Organization & 2 & 13.5 & 13 & 86.5 & 0.86 \\
\hline Scope & 1 & 6.5 & 14 & 93.5 & 0.93 \\
\hline
\end{tabular}

* Content Validity Index (CVI)

Table 3 - Second step of the judgment of the items of the protocol of prevention of the early infection by Streptococcus agalactiae in newborns. Recife, PE, Brazil, 2013.

\begin{tabular}{|c|c|c|c|c|c|}
\hline \multirow{3}{*}{ Items } & \multicolumn{4}{|c|}{ Judgment } & \multirow{3}{*}{$\mathrm{CVI}^{*}$} \\
\hline & \multicolumn{2}{|c|}{ Adequate with alterations } & \multicolumn{2}{|c|}{ Adequate } & \\
\hline & $\mathbf{n}$ & $\%$ & $\mathbf{N}$ & $\%$ & \\
\hline Vocabulary & - & - & 15 & 100 & 1.0 \\
\hline Relevance & - & - & 15 & 100 & 1.0 \\
\hline Clinical-Scentific Aspects & - & - & 15 & 100 & 1.0 \\
\hline Clarity & - & - & 15 & 100 & 1.0 \\
\hline Feasibility & 1 & 6.5 & 14 & 93.5 & 0.93 \\
\hline Organization & - & - & 15 & 100 & 1.0 \\
\hline Scope & - & - & 15 & 100 & 1.0 \\
\hline
\end{tabular}

* Content Validity Index (CVI) 
The most important questionings highlighted by the judges considered to be necessary for adjustments were related to the structure of the flowcharts, the adequacy of the vocabulary, the lack of description of the evidence levels, repeated information, the need for the elaboration of sentences more clearly and the inclusion of the diagram in the description of the prenatal conduct. For other questionings, clarifications were provided by personal contact established with the judge.

\section{Discussion}

Considering the titration of the judges and the minimum experience time of 10 years in almost all cases, adding that the HC/UFPE is a hospital-school in which the activities are together with the learning, research and extension inseparably, it is possible to state that it is an experienced group and it is inserted in a context that provides the opportunity for constant updating, suggesting that the judges possess the desirable qualification for the judgment of the protocol.

The obstetrics nurses are qualified to provide care for low-risk pregnancies during the prenatal period, for normal childbirth without dystocia and in the puerperium, in health facilities or at home. In case there is any complication during pregnancy that may characterize a high-risk pregnancy, these professionals should refer the pregnant woman to the doctor, so that he or she can continue to provide assistance. Keeping in mind that HC/UFPE is an institution specialized in the care of high-risk pregnancies, in which the care to these patients in the Prenatal and at the Obstetrics Center is given by the doctor - the sample did not include nurses.

The low-risk prenatal is done by the professionals that belong to the Program for the Family's Health (PSF), which is present in $92 \%$ of Brazilian cities. Given that, the doctors and nurses that act within the PSF need to pay attention to the importance of doing the microbiological exam for the detection of the $B$ group $\beta$-hemolitic Streptococcus. The challenge consists in, up to the present moment, the limited availability in the labs entailed to the Brazilian Sistema Único de Saúde (Unified Health System) for the prenatal routine, which suggests the need for stimulating the professionals to the introduction of the classification of the Streptococcus agalactiae between the $35^{\text {th }}$ and the $37^{\text {th }}$ weeks in the assessment of the pregnant women, in their respective local health facility.

Regarding the judgment process, it can be observed that the item Relevance obtained consensual total approval, which highlights the importance of doing the $s w a b$ in the pregnant women for the research of the B group $\beta$-hemolitic Streptococcus, as a way to orientate the prophylaxis and the treatment directed to the reduction of the prevalence of the neonatal infection by the group B Streptococcus are limited, provided that the recommendation for the universal tracking for the EGB research in all pregnant women between the $35^{\text {th }}$ and the $37^{\text {th }}$ weeks is not present in the manuals written by the Ministry of Health, which is restricted to special situations, such as: premature rupture of the membrane, premature labor and pregnant women that are HIV-positive.

The justification is based on a systematic review, that assessed the use of the intra-partum prophylactic antibiotic and the maternal and neonatal outcomes, making clear that, although there is a decrease in the occurrence of the infection caused by the EGB (RR 0.17 , CI $95 \%, 0.04$ to 0.74 ), there is a possibility that the results were influenced by the authors, due to a methodological flaw of the studies. The authors add that currently there are no satisfactory evidences to state that the intra-partum antibiotic prophylaxis is related to the reduction of the neonatal mortality due to this disease.

As the recognition of these controversies, related to the viability and the impact of the orientations published by the $C D C$, has a result in the lack of standardization of the preventive strategies in many countries and the uncertainty about the efficiency of these practices, recently a systematic review with meta-analysis, through an electronic query at the Cochrane Library, that had the goal of determining the best tracking strategy for the EGB in pregnant women. The results of this study demonstrated that the adoption of the universal tracking and of the antibiotic prophylaxis resulted in an important reduction in the incidence of the neonatal sepsis, making clear that the adoption of the universal tracking for pregnant women, added to the antibiotic prophylaxis, are efficient measures.

As the importance of this theme is considered in the context of Public Health, the City Department of Health of São Paulo published a technical note based on the CDC 2002 guide, for the tracking and prophylaxis of the EGB among the pregnant women registered in the Mãe Paulistana Program. Statistical data referring to the acquired infections in the perinatal period in the city of São Paulo demonstrate that there was a reduction from $57.8 \%$, in 2000 , to $55.1 \%$ in 2008 , and that can be related to the impact of the actions of the public policies 
regarding the care to the neonatal infection caused by the EGB.

It is of great importance that the tracking for the research of the EGB in all pregnant women between the $35^{\text {th }}$ and the $37^{\text {th }}$ weeks is included in the Ministry of Health's manuals, given that the indiscriminate use of antibiotics may entail an increase in the resistant strains. Furthermore, it is known that policies based on prevention result in a cost-effectiveness relation that is superior to the healing model.

At the HC/UFPE, the prophylaxis is based in the administration of crystalline penicillin in pregnant women that present risk factors. However, the impossibility of identifying the state of the maternal colonization can be interpreted as a risk for the transmission of the infection. This fact was demonstrated in the study conducted in pregnant women that have undergone intra-partum prophylaxis for the prevention of the maternal transmission of the EGB infection, based on risk factors in a maternity hospital in Minas Gerais, Brazil. The results revealed that $71.2 \%$ of the patients that received intra-partum prophylaxis according to their risk factors were not colonized by the EGB. On the other hand, $33.3 \%$ of the patients that did not receive the intra-partum prophylaxis were colonized. While the first piece of information may indicate that the clinical judgment led to the unnecessary use of antibiotics in around 7 out of 10 pregnant women, the second one indicates that the clinical judgment has flaws, provided that the colonized patients, that do not present risk factors, will not benefit from the prophylaxis.

The penicillin remains as the antibiotic of choice for the intra-partum prophylaxis, given that the EGB presents a considerable sensibility. On the other hand, a study done in a maternity hospital in Ceará, Brazil, demonstrated a high resistance in 4 out of 9 cases of pregnant women colonized by the Streptococcus agalactiae. This finding may be justified by the identification of molecular forms of these bacteria that present mutations in the gene of the protein of penicillin bonding, resulting in the reduction of the susceptibility to this medicine. Given that, the promotion of the rational use of the antibiotics becomes important, which was made possible through the development of the protocols. In the present study the protocol that was developed limited the chemo-prophylaxis, provided that in the pregnant women with a positive result for the culture this should only be indicated for the women colonized by the EGB or in the presence of asymptomatic bacteriuria, intra-partum fever, or a history of newborns stricken by the infection by the Streptococcus agalactiae in previous births.

It is worth highlighting that this study presented a limitation, provided that the validity of the content is a subjective process, being necessary a future validation through additional clinical application. This fact remits to the need for the conduction of future researches, with the intent of verifying the results of the application of the protocol in the neonatology and obstetrics sectors of the HC/UFPE.

\section{Conclusion}

The validation of the content done in this study was an effective tool to assess the adequacy of the protocol, in agreement with the judgment emitted by professionals with a wide experience in their area. According to the results that were obtained, after pondering the suggestions proposed by the judges, the content of the protocol for the prevention of the early neonatal sepsis by the Streptococcus agalactiae can be considered satisfactory and adequate, demonstrating the importance of doing a previous validation of the instruments. This first step represents an important phase in the validation process; however, the need for the production of studies should be highlighted, with the intention of submitting them to clinical applications.

Bearing in mind the serious consequences of the early perinatal streptococcal disease, in opposition to the methods of tracking of the B-group Streptococcus in the prenatal period, it is expected that this study works as an incentive to the adoption of the universal tracking by other institutions, both in the public and private healthcare systems, through validated protocols, based on the scientific knowledge that comes from researches based on the prevalence, prophylaxis and therapeutics of this relevant perinatal pathology.

\section{References}

1. Ministério da Saúde (BR). Atenção à saúde do recémnascido: guia para os profissionais de saúde. Brasília: Ministério da Saúde; 2011.

2. Castelano DS Filho, Tibiriça SHS, Diniz CG. Doença Perinatal associada aos estreptococos do Grupo B: aspectos clínico-microbiológicos e prevenção. HU Rev. 2008 abr/jun;34(2):127-34.

3. Stoll B, Hansen PS. Early Onset Neonatal Sepsis: The Burden of Group B Streptococcal and E. coli Disease Continues. Pediatrics2011 May;127(5):817. 
4. Springman AC, Latcher DW. Selection, recombination, and virulence gene diversity among group B streptococcal genotypes. J Bacteriol. 2009 Jul;19(1):5419-27.

5. Zaidi AKM, Thaver D, Ali SA, Khan TA. Pathogens Associated With Sepsis in Newborns and Young Infants in Developing Countries. Pediatr Infect Dis J. 2009 Jan; 28(19): 10-8.

6. Montes L, Souza JB, Fortunato FR Lopes ICR. Doença Perinatal Associada ao Streptococcus Agalactiae Aspectos Microbiológicos, Diagnóstico e Prevenção. News Lab. 2012; 109:132-43.

7. Prevention of perinatal group $B$ streptococcal disease: a public health perspective. MMWR 1996; Recomm Rep 45(RR-7): 1-24.

8. Schrag S, Zell E, Lynfield R, Aaron R. A populationbased comparison of strategies to prevent early-onset group B streptococcal disease in neonates. N Engl J Med. 2002;347(4):233.

9. Verani J, Mc gee L, Schrag S. Prevention of perinatal group B streptococcal disease - revised guidelines from CDC. MMWR 2010;59(RR-10):1-36.

10. Phares CR, Lynfield R, Farley MM, Mohle-Boetani J, Harrison LH, Petit S, et al. Epidemiology of invasive group B Streptococcal diseasein the United States, 1999-2005. J Am Med Assoc. 2008;299(17):2056-65.

11. Lukacs SL, Schrag SJ. Clinical Sepsis in Neonates and Young Infants, United States, 1988-2006. 2012;160(6):960-5.

12. Tibúrcio MP, Melo GSM, Balduíno LSC, Costa IKF, Dias TYAF, Torres GV. Validação de instrumento para avaliação da habilidade de mensuração da pressão arterial. Rev Bras Enferm. 2014; jul-ago;67(4):581-7.

13. Gusmão JL, Pierin AMG. Instrumento de Avaliação da Qualidade de Vida para Hipertensos de Bulpitt e Fletcher. Rev Esc Enferm USP. 2009; 43(Esp):1034-43.

14. Conselho Nacional de Saúde (BR). Resolução 466 [Internet]. [acesso 10 jul 2013]. Disponível em: http:// conselho.saude.gov.br/resolucoes/2012/Reso466.pdf 15. Ministério da Saúde (BR). Gestação de alto risco: manual técnico. 5ed. Brasília: Ministério da Saúde; 2012.

16. Ministério da Saúde (BR). Secretaria de atenção à saúde. Atenção Básica. Saúde da Família. Histórico de cobertura da Saúde da Família [Internet]. Brasília; 2008. [acesso 12 mar 2008]. Disponível em: http://dtr2004. saude.gov.br/dab/abnumeros.php.

17. Castellano-Filho DS, Silva VL, Nascimento TC, Vieira MT, Diniz CG. Detection of group b streptococcus in Brazilian pregnant women and antimicrobial susceptibility patterns. Braz J Microbiol. 2010;41:1047-55.
18. Ministério da Saúde (BR). Secretaria de Atenção à Saúde. Atenção ao pré-natal de baixo risco. Brasília: Ministério da Saúde; 2011.

19. Ohlsson A, Shah VS. Intrapartum antibiotics for known maternal Group B streptococcal colonization. Cochrane Data base Syst. Rev. 2009 jul; 8:(3).

20. Taminato M, Fram D, Torloni MR, Belasco AGS, Saconato $H$, Barbosa DA. Screening for group $B$ Streptococcus in pregnant women: a systematic review and meta-analysis. Rev. Latino-Am. Enfermagem. 2011;19(6):1470-8.

21. Prefeitura do Município de São Paulo. Secretaria Municipal da Saúde. Áreas Técnicas da Saúde da Mulher e da Criança e Assistência Laboratorial. Prevenção da infecção neonatal pelo Streptococcus agalactiae (Estreptococo Grupo B ou GBS). [acesso 13 out 2012]. Disponível em: www.prefeitura.sp.gov.br.

22. Nakamura PAM, Schuab RBB, Neves FPG, Pereira CFA, de Paula GR, Barros RR. Antimicrobial resistance profiles and genetic characterisation of macrolide resistant isolates of Streptococcus agalactiae. Mem Inst Oswaldo Cruz. 2011;106(2):119-22.

23. Linhares JJ, Cavalcante PG Neto. Prevalência de colonização por Streptococcus agalactiae em gestantes atendidas em maternidade do Ceará, no Brasil, correlacionando com os resultados perinatais. Rev Bras Ginecol Obstet. 2011; 33(12):395-400.

24. Kimura K, Suzuki S, Wachino J, Kurokawa H, Yamane $\mathrm{K}$, Shibata N, et al. First molecular characterization of group $B$ streptococci with reduced penicillin susceptibility. Antimicrobial Agents Chemother. 2008;52(8):2890-7. 